Matematikai Közlemények

VIII. kötet, 2020

doi:10.20312/dim.2020.03

\title{
Az általánosított hiperbolikus kvaternióalgebrákról
}

\author{
Péntek Kálmán \\ ELTE SEK TTMK Savaria Matematikai Tanszék \\ pentek.kalman@sek.elte.hu
}

\begin{abstract}
ÖSSZEFOGLALÓ. A dolgozatban elöször Macfarlane klasszikus M hiperbolikus kvaternióit általánosítjuk és megkonstruáljuk az általánosított hiperbolikus kvaterniók $\mathbb{M}_{\alpha \beta}$ nem kommutatív és nem asszociatív algebráját. Minden véges dimenziós asszociatív algebra izomorf egy teljes mátrixalgebra részalgebrájával, de az általánosított hiperbolikus kvaterniók $\mathbb{M}_{\alpha \beta}$ algbrája nem asszociatív. E probléma megoldására Zorn, M.A. definiálta a vektor-mátrix struktúrákat a split (hasított) oktoniók algebrájának leírására 1933-ban. A dolgozat utolsó fejezetében megkonstruáljuk az $\mathbb{M}_{\alpha \beta}$ általánosított hiperbolikus kvaterniók általánosított vektor-mátrix reprezentációját.
\end{abstract}

ABSTRACT. In the paper at first we generalize Macfarlane's classical hyperbolic quaternions $\mathrm{M}$, and we construct the non commutative and non associative algebras of generalized hyperbolic quaternions $\mathbb{M}_{\alpha \beta}$. Any finite dimensional associative algebra is algebrically isomorphic to a subalgebra of a total matrix algebra, but the algebras of generalized hyperbolic quaternions $\mathbb{M}_{\alpha \beta}$ is not associative. To overcome this problem Zorn, M.A. defined the vector-matrix structures for description split octonions algebra in 1933. In the last section of the paper we construct the generalized vector-matrix representation of generalized hyperbolic quaternions $\mathbb{M}_{\alpha \beta}$.

\section{Bevezetés}

Sir William Rowan Hamilton (1805 - 1865) ír matematikus, fizikus és csillagász 1833-ban dolgozta ki a klasszikus komplex számok $\mathbb{C}$ algebrájának a rendezett valós számpárokon alapuló felépítését (HAMILTON 1834,1837). A komplex számok használata hatékony és elegáns módszert kínált síkgeometriai problémák analitikus megoldására. Hamilton ezért kísérletezett a rendezett valós számhármasok algebrájának kidolgozásával, ettől remélte ugyanis a síkbeli esettel analóg módon a térgeometriai feladatok eredményes, analitikus módszerrel történő tárgyalását.

Csak 1843-ban ismerte fel, hogy célját rendezett valós számnégyesek segítségével érheti el és sikeresen meg is alkotta a $\mathbb{H}$ valós kvaterniók nem kommutatív, de asszociatív algebráját (HAMILTON 1844,1847). Élete hátralevő részét a kvaternióelmélet minél teljesebb kidolgozásának szentelte (ROSENFELD 1997, WARD 1997).

A valós kvaterniók algebráját Leonard Eugene Dickson (1874 - 1954) amerikai matematikus általánosította 1912-ben (DICKSON 1912), vélhetően Joseph Henry Maclagan Wedderburn (1882 - 1948) skót származású amerikai matematikus inspirációjára, és bevezette egy test feletti $\mathbb{H}_{\alpha \beta}$ általánosított kvaternióalgebra fogalmát (JAFARI - YAYLI 2015). E struktúra részletes magyarnyelvü bemutatását találhatjuk pl. Péntek K. dolgozatában (PÉNTEK 2018) 
A szintén skót származású amerikai matematikus és fizikus Alexander Macfarlane (1851 1913) 1891-ben alkotta meg Hamilton klasszikus kvaternióinak mintájára a hiperbolikus kvaterniók MI nem kommutatív és nem is asszociatív algebráját (MACFARLANE 1900).

Tudjuk, hogy minden véges dimenziós asszociatív algebra izomorf a megfelelően választott teljes mátrixalgebra alkalmas részalgebrájával, vagyis minden ilyen algebrának megadhatjuk a mátrix-reprezentációját. A nem asszociatív algebrák azonban nem reprezentálhatók mátrixokkal. Max August Zorn (1906 - 1993) német származású amerikai matematikus 1933ban viszont sikeresen reprezentálta a split (hasított) oktoniók nem kommutatív és nem asszociatív algebráját vektor-mátrixok segítségével (ZORN 1931, 1933, KARATAS - HALICI 2018).

Ebben a dolgozatban a Dickson által alkalmazott eljárással analóg módon általánosítjuk a klasszikus hiperbolikus kvaterniók $\mathbb{M}$ algebráját és értelmezzük az általánosított hiperbolikus kvaterniók $\mathbb{M}_{\alpha \beta}$ struktúráját, majd megvizsgáljuk algebrai tulajdonságait. A dolgozat fó eredményeként pedig megadjuk az $\mathbb{M}_{\alpha \beta}$ nem kommutatív és nem asszociatív algebrának alkalmas vektor-mátrixokkal történő reprezentációját.

\section{Az általánosított hiperbolikus kvaterniók}

\subsection{A Macfarlane-féle klasszikus hiperbolikus kvaterniók}

Legyen $\{\mathbb{R},+, \cdot\}$ a valós számok teste a 0 összeadási és 1 szorzási neutrális elemmel. Ekkor az

$$
\mathbb{M}:=\{a+b \cdot i+c \cdot j+d \cdot k: a, b, c, d \in \mathbb{R} ; i, j, k \notin \mathbb{R}\}
$$

alakú kifejezéseket a klasszikus hiperbolikus kvaterniók halmazának nevezzük, ha az $\{1, i, j, k\}$ kvaternióegységek eleget tesznek az alábbi szorzási szabályoknak:

$$
\begin{gathered}
1 \cdot 1=1, \quad 1 \cdot i=i \cdot 1=i, \quad 1 \cdot j=j \cdot 1=j, \quad 1 \cdot k=k \cdot 1=k \\
i^{2}=1, \quad j^{2}=1, \quad k^{2}=1 \\
i \cdot j=-j \cdot i=k, \quad j \cdot k=-k \cdot j=i, \quad k \cdot i=-i \cdot k=j .
\end{gathered}
$$

Az M halmazban értelmezhetünk skalárral való szorzást, összeadást és (2) felhasználásával a szokásos algebraszerkesztés homogén és disztributív szabályait követve szorzást is (KANTOR - SZOLODOVNYIKOV 1985) a következö módon. Tetszőleges

$$
r \in \mathbb{R}, a+b \cdot i+c \cdot j+d \cdot k, a^{\prime}+b^{\prime} \cdot i+c^{\prime} \cdot j+d^{\prime} \cdot k \in \mathbb{M}
$$

esetén a skalárral való szorzás:

$$
r \cdot(a+b \cdot i+c \cdot j+d \cdot k):=(r \cdot a)+(r \cdot b) \cdot i+(r \cdot c) \cdot j+(r \cdot d) \cdot k
$$

az összeadás:

a szorzás:

$$
\begin{gathered}
(a+b \cdot i+c \cdot j+d \cdot k)+\left(a^{\prime}+b^{\prime} \cdot i+c^{\prime} \cdot j+d^{\prime} \cdot k\right):= \\
\left(a+a^{\prime}\right)+\left(b+b^{\prime}\right) \cdot i+\left(c+c^{\prime}\right) \cdot j+\left(d+d^{\prime}\right) \cdot k
\end{gathered}
$$

$$
\begin{gathered}
(a+b \cdot i+c \cdot j+d \cdot k) \cdot\left(a^{\prime}+b^{\prime} \cdot i+c^{\prime} \cdot j+d^{\prime} \cdot k\right):= \\
\left(a \cdot b^{\prime}+b \cdot a^{\prime}+c \cdot d^{\prime}-d \cdot c^{\prime}\right) \cdot i+ \\
\left(a \cdot c^{\prime}-b \cdot d^{\prime}+c \cdot a^{\prime}+d \cdot b^{\prime}\right) \cdot j+ \\
\left(a \cdot d^{\prime}+b \cdot c^{\prime}-c \cdot b^{\prime}+d \cdot a^{\prime}\right) \cdot k
\end{gathered}
$$


A hiperbolikus kvaterniók $\mathbb{M}$ halmaza a rajta értelmezett (3), (4) és (5) müveletekkel egy 4-dimenziós, neutrális elemes, nem kommutatív és nem asszociatív algebrát alkot az $\mathbb{R}$ valós test felett.

A hiperbolikus kvaterniókat bemutató első dolgozat 1900-ban látott napvilágot az alkotó (MACFARLANE 1900) tárgyalásában, de napjainkban is fontos eredményekkel gazdagodik a téma szakirodalma (KÖSAL 2018).

\subsection{Az általánosított hiperbolikus kvaterniók}

L. E. Dickson klasszikus kvaterniók esetén alkalmazott módszerét követve (JAFARI-YAYLI 2015) most általánosítjuk a hiperbolikus kvaterniók fogalmát és megvizsgáljuk az így nyert struktúra legfontosabb algebrai tulajdonságait.

$\mathrm{Az}$

$$
\mathbb{M}_{\alpha \beta}:=\{a+b \cdot i+c \cdot j+d \cdot k: a, b, c, d \in \mathbb{R} ; i, j, k \notin \mathbb{R}\}
$$

alakú kifejezéseket az általánosított hiperbolikus kvaterniók halmazának nevezzük akkor és csakis akkor, ha az $\{1, i, j, k\}$ általánosított kvaternióegységek között teljesülnek az alábbi szorzási összefüggések:

$$
\begin{gathered}
1 \cdot 1=1, \quad 1 \cdot i=i \cdot 1=i, \quad 1 \cdot j=j \cdot 1=j, \quad 1 \cdot k=k \cdot 1=k \\
i^{2}=\alpha, \quad j^{2}=\beta, \quad k^{2}=\alpha \cdot \beta \\
i \cdot j=-j \cdot i=k, \quad j \cdot k=-k \cdot j=\beta \cdot i, \quad k \cdot i=-i \cdot k=\alpha \cdot j,
\end{gathered}
$$

ahol $\alpha, \beta \in \mathbb{R}$ rögzített valós paraméterek.

$\mathrm{Az} \mathbb{M}_{\alpha \beta}$ halmazban müveleteket értelmezhetünk, skalárral való szorzást és összeadást, továbbá a (7) alapján az algebraszerkesztés szabályait alkalmazva még egy szorzást is a következő módon. Tetszőleges

$$
r \in \mathbb{R}, a+b \cdot i+c \cdot j+d \cdot k, a^{\prime}+b^{\prime} \cdot i+c^{\prime} \cdot j+d^{\prime} \cdot k \in \mathbb{M}_{\alpha \beta}
$$

esetén a skalárral való szorzás:

$$
r \cdot(a+b \cdot i+c \cdot j+d \cdot k):=(r \cdot a)+(r \cdot b) \cdot i+(r \cdot c) \cdot j+(r \cdot d) \cdot k
$$

az összeadás:

$$
\begin{gathered}
(a+b \cdot i+c \cdot j+d \cdot k)+\left(a^{\prime}+b^{\prime} \cdot i+c^{\prime} \cdot j+d^{\prime} \cdot k\right):= \\
\left(a+a^{\prime}\right)+\left(b+b^{\prime}\right) \cdot i+\left(c+c^{\prime}\right) \cdot j+\left(d+d^{\prime}\right) \cdot k
\end{gathered}
$$

a szorzás:

$$
\begin{gathered}
(a+b \cdot i+c \cdot j+d \cdot k) \cdot\left(a^{\prime}+b^{\prime} \cdot i+c^{\prime} \cdot j+d^{\prime} \cdot k\right):= \\
\left(a \cdot a^{\prime}+\alpha \cdot b \cdot b^{\prime}+\beta \cdot c \cdot c^{\prime}+\alpha \cdot \beta \cdot d \cdot d^{\prime}\right)+ \\
\left(a \cdot b^{\prime}+b \cdot a^{\prime}+\beta \cdot c \cdot d^{\prime}-\beta \cdot d \cdot c^{\prime}\right) \cdot i+ \\
\left(a \cdot c^{\prime}-\alpha \cdot b \cdot d^{\prime}+c \cdot a^{\prime}+\alpha \cdot d \cdot b^{\prime}\right) \cdot j+ \\
\left(a \cdot d^{\prime}+b \cdot c^{\prime}-c \cdot b^{\prime}+d \cdot a^{\prime}\right) \cdot k
\end{gathered}
$$

1. Tétel. Az általánosított hiperbolikus kvaterniók $\mathbb{M}_{\alpha \beta}$ halmaza a rajta értelmezett (8),(9) és (10) műveletekkel egy 4-dimenziós, neutrális elemes, de nem kommutatív és nem asszociatív algebrát alkot a valós számok $\mathbb{R}$ teste felett. 
Megjegyzés. A (7) összefüggés 3. sorából közvetlenül látható, hogy a (10) szorzás nem kommutatív és nem asszociatív. Valóban, pl. $i \cdot j=k, j \cdot i=-k$, tehát $i \cdot j \neq j \cdot i$, így a szorzás nem kommutatív általában. Másrészt, pl. $(i \cdot j) \cdot j=k \cdot j=-\beta \cdot i, i \cdot(j \cdot j)=i \cdot \beta=$ $\beta \cdot i$, ezért $(i \cdot j) \cdot j \neq i \cdot(j \cdot j)$, így a szorzás nem asszociatív általában.

Speciálisan, ha $\alpha=\beta=1$, akkor éppen $\mathbb{M}_{\alpha \beta}=\mathbb{M}$ teljesül.

Definició. A $q:=a+b \cdot i+c \cdot j+d \cdot k \in \mathbb{M}_{\alpha \beta}$ konjugáltján a $\bar{q}=a-b \cdot i-c \cdot j-d \cdot k \in$ $\mathbb{M}_{\alpha \beta}$ elemet értjük.

2. Tétel. Ha $r \in \mathbb{R}, q, q^{\prime} \in \mathbb{M}_{\alpha \beta}$, akkor a konjugált képzésére érvényesek a következő tulajdonságok:
(a)
(b) $\quad \overline{r \cdot q}=r \cdot \bar{q}$
$\overline{\bar{q}}=q$
involutív,
(c) $\overline{q+q^{\prime}}=\bar{q}+\overline{q^{\prime}}$
(d) $\overline{q \cdot q^{\prime}}=\overline{q^{\prime}} \cdot \bar{q}$
homogén,
additív,
anti-multiplikatív.

3. Tétel. Ha $q=a+b \cdot i+c \cdot j+d \cdot k \in \mathbb{M}_{\alpha \beta}$, akkor érvényes a

$$
q \cdot \bar{q}=\bar{q} \cdot q=a^{2}-\alpha \cdot b^{2}-\beta \cdot c^{2}-\alpha \cdot \beta \cdot d^{2} \in \mathbb{R}
$$

összefüggés.

Definíció. A $q:=a+b \cdot i+c \cdot j+d \cdot k \in \mathbb{M}_{\alpha \beta}$ elem normáján a

$$
N(q):=a^{2}-\alpha \cdot b^{2}-\beta \cdot c^{2}-\alpha \cdot \beta \cdot d^{2}
$$

valós számot értjük.

4. Tétel. Ha $q, q^{\prime} \in \mathbb{M}_{\alpha \beta}$ tetszőleges elemek, akkor

(a) $\quad N(q)=N(\bar{q})$,

(b) $\quad N\left(q \cdot q^{\prime}\right) \neq N(q) \cdot N\left(q^{\prime}\right)$ általában.

Megjegyzés. A normafüggvény általában nem multiplikatív, ugyanis pl. $N(i \cdot j)=N(k)=$ $-\alpha \cdot \beta$, másrészt $N(i) \cdot N(j)=(-\alpha) \cdot(-\beta)=\alpha \cdot \beta$, tehát $N(i \cdot j) \neq N(i) \cdot N(j)$.

Definíció. Ha $q=a+b \cdot i+c \cdot j+d \cdot k, q^{\prime}=a^{\prime}+b^{\prime} \cdot i+c \cdot j+d^{\prime} \cdot k \in \mathbb{M}_{\alpha \beta}$, akkor e két elem skaláris szorzatán a

$$
\left\langle q, q^{\prime}\right\rangle:=a \cdot a^{\prime}-\alpha \cdot b \cdot b^{\prime}-\beta \cdot c \cdot c^{\prime}-\alpha \cdot \beta \cdot d \cdot d^{\prime} \in \mathbb{R}
$$

valós számot értjük.

5. Tétel. A skaláris szorzat képzése egy $\mathbb{M}_{\alpha \beta} \times \mathbb{M}_{\alpha \beta} \rightarrow \mathbb{R}$ szimmetrikus bilineáris leképezés, tetszőleges $r \in \mathbb{R}, q, q^{\prime}, q^{\prime \prime} \in \mathbb{M}_{\alpha \beta}$ esetén
(a)

$$
\begin{gathered}
\left\langle q, q^{\prime}\right\rangle=\left\langle q^{\prime}, q\right\rangle \\
\left\langle r \cdot q, q^{\prime}\right\rangle=\left\langle q, r \cdot q^{\prime}\right\rangle=r \cdot\left\langle q, q^{\prime}\right\rangle \\
\left\langle q, q^{\prime}+q^{\prime \prime}\right\rangle=\left\langle q, q^{\prime}\right\rangle+\left\langle q, q^{\prime \prime}\right\rangle
\end{gathered}
$$$$
\text { (d) } \quad\left\langle q+q^{\prime}, q^{\prime \prime}\right\rangle=\left\langle q, q^{\prime \prime}\right\rangle+\left\langle q^{\prime}, q^{\prime \prime}\right\rangle
$$
kommutatív, homogén, balról disztributív, jobbról disztributív.

Látható, hogy egy általánosított hiperbolikus kvaternió normája a skaláris szorzatból származtatható, hiszen ha $q \in \mathbb{M}_{\alpha \beta}$, akkor a norma és a skaláris szorzat fenti értelmezése szerint $N(q)=\langle q, q\rangle$ teljesül. 
6. Tétel. Tetszőleges $q=a+b \cdot i+c \cdot j+d \cdot k, q^{\prime}=a^{\prime}+b^{\prime} \cdot i+c^{\prime} \cdot j+d^{\prime} \cdot k \in \mathbb{M}_{\alpha \beta}$ elempár skaláris szorzata előállítható a következő

$$
\left\langle q, q^{\prime}\right\rangle=(a, b, c, d) \cdot\left(\begin{array}{cccc}
1 & 0 & 0 & 0 \\
0 & -\alpha & 0 & 0 \\
0 & 0 & -\beta & 0 \\
0 & 0 & 0 & -\alpha \beta
\end{array}\right) \cdot\left(\begin{array}{l}
a^{\prime} \\
b^{\prime} \\
c^{\prime} \\
d^{\prime}
\end{array}\right)
$$

alakban.

Megjegyzés. A 6.T. előállításából jól látható, hogy az $\alpha=\beta=1$ esetén adódó klasszikus $\mathbb{M}$ hiperbolikus kvaterniók egy Minkowski metrikájú algebrát alkotnak.

Definíció. Az $\mathbb{R}$ feletti $\mathcal{A}$ egy alternáló algebra akkor és csakis akkor, ha bármely $x, y \in \mathcal{A}$ esetén teljesül az $(x \cdot x) \cdot y=x \cdot(x \cdot y)$ és az $(x \cdot y) \cdot y=x \cdot(y \cdot y)$ azonosság.

7. Tétel. Az $\mathbb{M}_{\alpha \beta}$ algebra nem alternáló.

BizonyítÁs. Egyrészt $(i \cdot i) \cdot j=\alpha \cdot j$ és $i \cdot(i \cdot j)=i \cdot k=-\alpha \cdot j$, így $(i \cdot i) \cdot j \neq i \cdot(i \cdot j)$. Másrészt $(i \cdot j) \cdot j=k \cdot j=-\beta \cdot i$ és $i \cdot(j \cdot j)=i \cdot \beta=\beta \cdot i$, ezért $(i \cdot j) \cdot j \neq i \cdot(j \cdot j)$.

Definíció. Az $\mathbb{R}$ feletti, $e$ neutrális elemes $\mathcal{A}$ egy kvadratikus algebra akkor és csakis akkor, ha bármely $x \in \mathcal{A}$ estén létezik olyan $\lambda, \mu \in \mathbb{R}$, hogy $x^{2}=\lambda \cdot e+\mu \cdot x$ elöállítás adható meg.

8. Tétel. $\mathrm{Az} \mathbb{M}_{\alpha \beta}$ egy kvadratikus algebra.

BizonyítÁs. Ha $x=a+b \cdot i+c \cdot j+d \cdot k \in \mathbb{M}_{\alpha \beta}$ tetszőleges, akkor az $x^{2}=\lambda \cdot 1+\mu \cdot$ $x$ egyenlet mindig megoldható a $\lambda, \mu \in \mathbb{R}$ ismeretlenekre, $\mathrm{s}$ a megoldás:

$$
\lambda=-a^{2}+\alpha \cdot b^{2}+\beta \cdot c^{2}+\alpha \cdot \beta \cdot d^{2} \text { és } \mu=2 \cdot a,
$$

ami az állítást bizonyítja.

Megjegyzés. Vegyük észre, hogy a fenti tételben szereplő $x \in \mathbb{M}_{\alpha \beta}$ elemre teljesül $N(x)=$ $-\lambda$, továbbá $t(x)=\mu$, ahol $t(x)$ éppen az $x \in \mathbb{M}_{\alpha \beta}$ elemhez hozzárendelt vektor-mátrix nyoma (lásd alább). Az $\mathbb{M}_{\alpha \beta}$ algebra kvadratikus voltát leíró összefüggés így az $x^{2}=$ $-N(x)+t(x) \cdot x$, vagyis az $x^{2}-t(x) \cdot x+N(x)=0$ alakot ölti.

Megjegyzés. Jól ismert eredmény, hogy minden véges dimenziós alternáló algebra kvadratikus (EBBINGHAUS ET AL. 1991), így a fentiek szerint az $\mathbb{M}_{\alpha \beta}$ egy olyan $\mathbb{R}$ feletti 4-dimenziós, neutrális elemes, nem kommutatív és nem asszociatív algebra, amelyik kvadratikus, de nem alternáló algebra.

\subsection{Az általánosított hiperbolikus kvaterniók vektorgeometriája}

Definíció. A $q=a+b \cdot i+c \cdot j+d \cdot k \in \mathbb{M}_{\alpha \beta}$ tetszőleges általánosított hiperbolikus kvaternió valós részén (skalár rész) az

$$
S(q):=a \in \mathbb{R}
$$

valós számot, képzetes részén (vektor rész) pedig a

$$
V(q):=b \cdot i+c \cdot j+d \cdot k \in \mathbb{R}^{3}
$$

vektort értjük. 
Definíció. Az $\operatorname{Im}\left(\mathbb{M}_{\alpha \beta}\right):=\left\{0+b \cdot i+c \cdot j+d \cdot k \in \mathbb{M}_{\alpha \beta}\right\} \subset \mathbb{M}_{\alpha \beta}$ alakú általánosított hiperbolikus kvaterniókat tiszta képzetes kvaternióknak nevezzük.

Legyen $q:=b \cdot i+c \cdot j+d \cdot k, \quad q^{\prime}:=b^{\prime} \cdot i+c^{\prime} \cdot j+d^{\prime} \cdot k \in \operatorname{Im}\left(\mathbb{M}_{\alpha \beta}\right)$ két tiszta képzetes hiperbolikus kvaternió, akkor szorzatuk

$$
\begin{aligned}
q \cdot q^{\prime}: & =-\left(-\alpha \cdot b \cdot b^{\prime}-\beta \cdot c \cdot c^{\prime}-\alpha \cdot \beta \cdot d \cdot d^{\prime}\right)+ \\
& {\left[\left(c \cdot d^{\prime}-d \cdot c^{\prime}\right) \cdot \beta \cdot i+\left(d \cdot b^{\prime}-b \cdot d^{\prime}\right) \cdot \alpha \cdot j+\left(b \cdot c^{\prime}-c \cdot b^{\prime}\right) \cdot k\right] }
\end{aligned}
$$

lesz, ez indokolja a következő kettős definíciót.

Definíció. Két tiszta képzetes hiperbolikus kvaternió skaláris szorzatán a

$$
q \circ q^{\prime}:=-\alpha \cdot b \cdot b^{\prime}-\beta \cdot c \cdot c^{\prime}-\alpha \cdot \beta \cdot d \cdot d^{\prime} \in \mathbb{R}
$$

valós számot, vektoriális szorzatán pedig a

$$
q \times q^{\prime}:=\left(c \cdot d^{\prime}-d \cdot c^{\prime}\right) \cdot \beta \cdot i+\left(d \cdot b^{\prime}-b \cdot d^{\prime}\right) \cdot \alpha \cdot j+\left(b \cdot c^{\prime}-c \cdot b^{\prime}\right) \cdot k \in \mathbb{R}^{3}
$$

vektort értjük.

Megjegyzés. Ekkor tehát érvényes a $q \cdot q^{\prime}=-q \circ q^{\prime}+q \times q^{\prime}$ összefüggés. A tiszta képzetes hiperbolikus kvaterniók o skaláris szorzata az általános hiperbolikus kvaterniók $\langle$,$\rangle skaláris$ szorzatának leszükítése, vagyis ha $q, q^{\prime} \in \operatorname{Im}\left(\mathbb{M}_{\alpha \beta}\right)$, akkor $q \circ q^{\prime}=\left\langle q, q^{\prime}\right\rangle$.

9. Tétel. A $\circ: \operatorname{Im}\left(\mathbb{M}_{\alpha \beta}\right) \times \operatorname{Im}\left(\mathbb{M}_{\alpha \beta}\right) \rightarrow \mathbb{R}$ skaláris szorzat egy szimmetrikus bilineáris leképezés, tetszőleges $r \in \mathbb{R}, q, q^{\prime}, q^{\prime \prime} \in \operatorname{Im}\left(\mathbb{M}_{\alpha \beta}\right)$ esetén
(a)
$q \circ q^{\prime}=q^{\prime} \circ q$
kommutatív,

$$
q \circ\left(q^{\prime}+q^{\prime \prime}\right)=q \circ q^{\prime}+q \circ q^{\prime \prime}
$$$$
(r \cdot q) \circ q^{\prime}=q \circ\left(r \cdot q^{\prime}\right)=r \cdot\left(q \circ q^{\prime}\right)
$$$$
\left(q+q^{\prime}\right) \circ q^{\prime \prime}=q \circ q^{\prime \prime}+q^{\prime} \circ q^{\prime \prime}
$$
homogén,
balról disztributív,
jobbról disztributív.

10. Tétel. Az $\quad \times: \operatorname{Im}\left(\mathbb{M}_{\alpha \beta}\right) \times \operatorname{Im}\left(\mathbb{M}_{\alpha \beta}\right) \rightarrow \operatorname{Im}\left(\mathbb{M}_{\alpha \beta}\right)$ vektoriális szorzat egy antiszimmetrikus bilineáris leképezés, tetszőleges $r \in \mathbb{R}, q, q^{\prime}, q^{\prime \prime} \in \operatorname{Im}\left(\mathbb{M}_{\alpha \beta}\right)$ esetén
(a) $q^{\prime} \times q=-q \times q^{\prime}$ anti-kommutatív,
(b) $(r \cdot q) \times q^{\prime}=q \times\left(r \cdot q^{\prime}\right)=r \cdot\left(q \times q^{\prime}\right)$ homogén,
(c) $\quad q \times\left(q^{\prime}+q^{\prime \prime}\right)=q \times q^{\prime}+q \times q^{\prime \prime}$ balról disztributív,
(d) $\quad\left(q+q^{\prime}\right) \times q^{\prime \prime}=q \times q^{\prime \prime}+q^{\prime} \times q^{\prime \prime}$ jobbról disztributív,
(e) $\quad q \times q=\mathbf{0}$,

ahol $\mathbf{0}:=0 \cdot i+0 \cdot j+0 \cdot k \in \operatorname{Im}\left(\mathbb{M}_{\alpha \beta}\right)$ a zérusvektor.

Megjegyzés. $(i \times j) \times j=k \times j=-\beta \cdot i$ és $i \times(j \times j)=i \times \mathbf{0}=\mathbf{0}$, ezért $(i \times j) \times j \neq i \times$ $(j \times j)$, vagyis a vektoriális szorzat az $\operatorname{Im}\left(\mathbb{M}_{\alpha \beta}\right)$ halmazban általában nem asszociatív.

Definíció. Ha $q, q^{\prime}, q^{\prime \prime} \in \operatorname{Im}\left(\mathbb{M}_{\alpha \beta}\right)$, akkor ezen elemek ilyen sorrendben képezett vegyesszorzatán a

$$
q q^{\prime} q^{\prime \prime}:=\left(q \times q^{\prime}\right) \circ q^{\prime \prime} \in \mathbb{R}
$$

valós számot értjük. 
11. Tétel. Ha $q, q^{\prime}, q^{\prime \prime} \in \operatorname{Im}\left(\mathbb{M}_{\alpha \beta}\right)$, akkor

(a) $\quad q q^{\prime} q^{\prime \prime}=-\alpha \cdot \beta \cdot \operatorname{det}\left(q, q^{\prime}, q^{\prime \prime}\right)$,

(b) $\quad q q^{\prime} q=\left(q \times q^{\prime}\right) \circ q=0$,

(c) $\left(q \times q^{\prime}\right) \circ q^{\prime \prime}=q \circ\left(q^{\prime} \times q^{\prime \prime}\right)$ (invariancia tulajdonság).

Következmény. Ha $q, q^{\prime}, q^{\prime \prime} \in \operatorname{Im}\left(\mathbb{M}_{\alpha \beta}\right)$, akkor $q q^{\prime} q^{\prime \prime}=q^{\prime} q^{\prime \prime} q=q^{\prime \prime} q q^{\prime}$ (felcserélési tulajdonság).

12. Tétel. (GRASSMANN - azonosság, kifejtési tétel). Bármely $a, b, c \in \operatorname{Im}\left(\mathbb{M}_{\alpha \beta}\right)$ esetén érvényesek:

$$
\begin{aligned}
& (a \times b) \times c=-[(a \circ c) \cdot b-(b \circ c) \cdot a] \\
& a \times(b \times c)=-[(a \circ c) \cdot b-(a \circ b) \cdot c] .
\end{aligned}
$$

13. Tétel. (JACOBI - azonosság.) Bármely $a, b, c \in \operatorname{Im}\left(\mathbb{M}_{\alpha \beta}\right)$ elemekre érvényesek:

$$
\begin{aligned}
& (a \times b) \times c+(b \times c) \times a+(c \times a) \times b=\mathbf{0}, \\
& a \times(b \times c)+b \times(c \times a)+c \times(a \times b)=\mathbf{0} .
\end{aligned}
$$

14. Tétel. (LAGRANGE - azonosság.) Bármely $a, b, c, d \in \operatorname{Im}\left(\mathbb{M}_{\alpha \beta}\right)$ elemek esetén érvényes:

$$
(a \times b) \circ(c \times d)=-\left|\begin{array}{lll}
a \circ c & a \circ d \\
b \circ c & b \circ d
\end{array}\right| \text {. }
$$

Speciálisan, ha $a=c, b=d$, akkor igaz a

15. Tétel. (Speciális LAGRANGE - azonosság.) Bármely $a, b \in \operatorname{Im}\left(\mathbb{M}_{\alpha \beta}\right)$ elemekre érvényes:

$$
(a \times b) \circ(a \times b)=-[(a \circ a) \cdot(b \circ b)-(a \circ b) \cdot(a \circ b)] .
$$

Az $\times$ vektoriális szorzás müvelet 10. Tétel. (e) tulajdonsága, e müvelet nem asszociatív tulajdonsága és a 13. Tétel elsö összefüggése alapján érvényes a következő

16. Tétel. $\operatorname{Az}\left\{\operatorname{Im}\left(\mathbb{M}_{\alpha \beta}\right),+, \times\right\}$ algebrai struktúra egy LIE algebra.

\subsection{Az általánosított hiperbolikus kvaterniók vektor-mátrix reprezentációja}

Definíció. A $Z(\mathbb{R}):=\left\{\left(\begin{array}{ll}A_{11} & A_{12} \\ A_{21} & A_{22}\end{array}\right): A_{11}, A_{22} \in \mathbb{R}, A_{12}, A_{21} \in \mathbb{R}^{3}\right\} \quad$ alakú hipermátrixok halmazát Zorn - féle vektor-mátrixoknak nevezzük. A $Z(\mathbb{R})$ halmazban müveleteket értelmezünk a következő módon. Ha $r \in \mathbb{R}, A, B \in Z(\mathbb{R})$, akkor a skalárral való szorzás:

$$
r \cdot A=r \cdot\left(\begin{array}{ll}
A_{11} & A_{12} \\
A_{21} & A_{22}
\end{array}\right):=\left(\begin{array}{ll}
r \cdot A_{11} & r \cdot A_{12} \\
r \cdot A_{21} & r \cdot A_{22}
\end{array}\right)
$$

az összeadás:

$$
A+B=\left(\begin{array}{ll}
A_{11} & A_{12} \\
A_{21} & A_{22}
\end{array}\right)+\left(\begin{array}{ll}
B_{11} & B_{12} \\
B_{21} & B_{22}
\end{array}\right):=\left(\begin{array}{ll}
A_{11}+B_{11} & A_{12}+B_{12} \\
A_{21}+B_{21} & A_{22}+B_{22}
\end{array}\right)
$$

a szorzás: 


$$
\begin{gathered}
A * B=\left(\begin{array}{ll}
A_{11} & A_{12} \\
A_{21} & A_{22}
\end{array}\right) *\left(\begin{array}{ll}
B_{11} & B_{12} \\
B_{21} & B_{22}
\end{array}\right):= \\
\left(\begin{array}{cc}
A_{11} \cdot B_{11}+A_{12} \circ B_{21} & A_{11} \cdot B_{12}+B_{22} \cdot A_{12}+A_{21} \times B_{21} \\
B_{11} \cdot A_{21}+A_{22} \cdot B_{21}-A_{12} \times B_{12} & A_{22} \cdot B_{22}+A_{21} \circ B_{12}
\end{array}\right) .
\end{gathered}
$$

E müveletek értelmezése során az $\mathbb{R}$, illetve az $\mathbb{R}^{3}$ müveleteit, továbbá az $\operatorname{Im}\left(\mathbb{M}_{\alpha \beta}\right)$ struktúra ○ skaláris szorzása és $\times$ vektoriális szorzása müveleteit használtuk fel.

17. Tétel. A $Z(\mathbb{R})$ halmaz a (11), (12) és (13) müveletekkel egy 8-dimenziós, neutrális elemes, de nem kommutatív és nem is asszociatív algebrát alkot az $\mathbb{R}$ test felett.

Definíció. Jelölje $Z_{\mathbb{M}}(\mathbb{R})$ azon speciális alakú Zorn-féle vektor-mátrixok halmazát, amelyre teljesülnek az

$$
A_{11}=A_{22}=a \in \mathbb{R} \quad \text { és } \quad A_{12}=-A_{21}:=(b, c, d) \in \mathbb{R}^{3}
$$

összefüggések.

18. Tétel. $A Z_{\mathbb{M}}(\mathbb{R})$ halmaz a (11), (12) és (13) műveletekkel egy 4-dimenziós, neutrális elemes, de nem kommutatív és nem is asszociatív részalgebrát alkot a $Z(\mathbb{R})$ algebrában.

19. Tétel. Az

$$
\begin{aligned}
F: \mathbb{M}_{\alpha \beta} & \rightarrow Z_{\mathbb{M}}(\mathbb{R}), \\
a+b \cdot i+c \cdot j+d \cdot k & \mapsto\left(\begin{array}{cc}
a & (b, c, d) \\
-(b, c, d) & a
\end{array}\right)
\end{aligned}
$$

leképezés egy algebra-izomorfizmus, vagyis egy bijektív és müvelettartó leképezés, amelyre tetszőleges $r \in \mathbb{R}, q, q^{\prime} \in \mathbb{M}_{\alpha \beta}$ esetén teljesül:
(a)
$F(r \cdot q)=r \cdot F(q)$
(c)$$
F\left(q+q^{\prime}\right)=F(q)+F\left(q^{\prime}\right)
$$
homogén,
additív,

$$
F\left(q \cdot q^{\prime}\right)=F(q) * F\left(q^{\prime}\right)
$$
multiplikatív

összefüggés.

A fenti tétel az $\mathbb{M}_{\alpha \beta}$ algebra vektor-mátrix reprezentációja.

\section{Irodalomjegyzék}

[1] Dickson, L. E., Linear algebras. Trans. Amer. Math. Soc. 13(1), (1912) 59-73.

[2] Ebbinghaus, H. D., Hermes, H., Hirzebruch, F., Koecher, M., Mainzer, K. Neukirch, J., Prestel, A., Remmert, R, Numbers. Springer, 1991.

[3] Hamilton, W. R., On Conjugate function, or algebraic Couples. British Association Report, Edinburg. (1834) 519-523.

[4] Hamilton, W. R., Theory of conjugate functions, or algebraic couples; with a Preliminary and elementary essay on algebra as the science of pure time. Transactions of the Royal Irish Academy, 17(1), (1837) 293422 .

[5] Hamilton, W. R., On a new Species of Imaginary quantities connected with a Theory of quaternions. Proceedings of the Royal Irish Academy, 2 (1844) 424-434.

[6] Hamilton, W. R., On Quaternions. Proceedings of the Royal Irish Academy, 3 (1847) 1-16.

[7] Jafari, M., Yayli, Y., Generalized Quaternions and Their Algebraic Properties. Commun. Fac. Sci. Univ. Ank. Ser. A1, 64(1), (2015) 15-27. doi:10.1501/Commua1_0000000724.

[8] Kantor, I. L., Szolodovnyikov, A. Sz., Hiperkomplex számok. Gondolat, Bp., 1985.

[9] Karatas, A., Halici, S., Vector Matrix Representation of Octonions and Their Geometry. Commun. Fac. Sci. Univ. Ank. Ser. A1 67(1), (2018) 161-167. doi:10.1501/Commua1_0000000839

[10] Kösal, I. A. A note on hyperbolic quaternions. Universal Journal of Mathematics and Applications, I(3), (2018) 155-159.

[11] Macfarlane, A. Hyperbolic Quaternions. Proceedings of the Royal Society at Edinburgh. vol. 23. (2018) 169 - 180 +figures plate. 
[12] Péntek, K., Az általánosított kvaternióalgebrák egy új felépítéséröl. Dimenziók, Matematikai Közlemények, VI. (2018) 25-30. doi:10.20312/dim.2018.03

[13] Rosenfeld, B., Geometry of Lie groups. Kluwer Academic Publisher, Netherlands, 1997. doi:10.1007/9781-4757-5325-7

[14] Ward, J. P., Quaternions and Cayley Numbers. Spinger Science, Bussines Media B.V, 1997.

[15] Zorn M.A. Theorie der alternativen Ringe. In: Abhandlungen aus dem Mathematischen Seminar der Universitat Hamburg. Springer Berlin/Heidelberg, (1931) 123-147.

[16] Zorn, M. A., Alternativkörper und quadratische Systeme. In: Abhandlungen aus dem Mathematischen Seminar der Universitat Hamburg. Springer Berlin/Heidelberg, (1933) 395-402. 